\title{
A Comparative Study of Interscalene Block Vs. Interscalene Block with Superficial Cervical Plexus Block for Clavicular Plating
}

\author{
Regmi NK ${ }^{1}$, Pokhrel $K^{2}$
}

\begin{abstract}
Background: Regional anaesthesia for fixation of clavicle fracture is a new concept. Various techniques of regional anaesthesia are being tried to find the optimal type. Combined interscalene and superficial cervical plexus block is widely accepted. Aim of Study: This study aims to compare the efficacy of interscalene block (ISB) with combined interscalene block and superficial cervical plexus block (ISB+ SCPB) for clavicular plating. Material and Methods: This prospective, hospital based comparative study was conducted from March 2019 to October 2019, in the department of anaesthesiology, Nepalgunj Medical College. 60 ASA category I and II patients undergoing clavicular plating and belonging to age group 16-65 years were enrolled. Patients were divided into two groups: Group I: ISB (n=30), Group II: ISB+ SCPB $(n=30)$. Blocks were given using landmark technique. Primary outcome measures were conversion to general anesthesia (GA), requirement of supplemental analgesia and patient satisfaction. Secondary outcome measures were sensory and motor block, duration of analgesia and complications. These outcome measures were compared between the groups. Results: No patient required conversion to GA. The number of patient requiring supplemental analgesia was significantly higher in ISB group in comparison to ISB+ SCPB. Patient satisfaction was excellent in both groups. No statistically significant complications were seen in either group. Conclusion: Interscalene block combined with Superficial Cervical Plexus Block (ISB + SCPB) has better efficacy than Interscalene block (ISB) alone for clavicular plating. Nevertheless, both techniques avoid GA and provide excellent patient satisfaction level.
\end{abstract}

Key Words: Interscalene Block (ISB), Superficial Cervical Plexus Block (SCPB), Clavicular Plating, Land Mark Technique, General Anesthesia (GA).

$$
\begin{aligned}
& \text { Dr. Nabin Kumar Regmi } \\
& \text { Dr. Kapil Pokhrel }
\end{aligned}
$$

Address for Correspondence:

Dr. Nabin Kumar Regmi
Assistant Professor
Department of Anaesthesia
Nepalgunj Medical College
Mobile no: 9849210099
Email: nabinkums@gmail.com

\section{INTRODUCTION}

Clavicle fracture constitutes $5-10 \%$ of all fractures. Operative repair is considered in patients with risk factors for non union ${ }^{1}$. Surgical fixation of clavicle fractures are often performed under general anesthesia (GA), as it is difficult to block all the nerves supplying the concerned surgical areas ${ }^{2}$. The suprascapular, supraclavicular, subclavian and the long thoracic nerves are hypothesized for the pain transmission after clavicle fractures ${ }^{3}$.

Recently anesthesiologists have started regional anesthesia for clavicular plating. Use of Interscalene block (ISB), superficial cervical plexus block (SCPB) and selective upper trunk block as single block techniques and SCPB combined with either ISB or supraclavicular blocks (SCB) as combined block techniques are reported in literatures ${ }^{4,5,6}$.

ISB + SCPB technique is widely accepted as regional anesthesia technique for the clavicle surgery ${ }^{5}$. ISB has an advantage that it often blocks cervical plexus and some studies have shown that clavicular plating can be done in ISB alone ${ }^{7,8}$. Hence, we conducted this study to find out whether ISB alone or ISB + SCPB is better.

\section{MATERIAL AND METHODS}

This is a prospective, hospital based comparative study. This study was conducted from March 2019 to October 2019, for a period of 8 months, in the department of anaesthesiology, Nepalgunj Medical College, after taking approval from Institutional Review Committee. 60 patients who were undergoing plating for clavicle fractures were enrolled in the study. These patients were divided into two groups:

Group I ( $n=30):$ ISB \{Lignocaine with adrenaline (1:200000) $5.5 \mathrm{ml}+$ Bupivacaine $5.5 \mathrm{ml}+$ Normal Saline 5 $\mathrm{ml}$, total $16 \mathrm{ml}\}$

Group II $(n=30):$ ISB + SCPB (ISB dose + same concentration $10 \mathrm{ml}$ solution for SCPB)

Patients with age below 16 years and above 65 years, ASA grade III and IV, bleeding disorders, respiratory compromise, local site infection, neurological deficit on the side of the surgery and reluctant for regional anesthesia were excluded from the study.

On arrival of the patients to the operation room, placement and patency of IV canula were checked. Patients were reassessed 
and noninvasively monitored. They were alternately allotted to group I and Group II to avoid bias.

Using landmark technique, at the level of cricoid cartilage and lateral to the lateral border of sternocleidomastoid muscle, the interscalene groove was identified with finger roll technique. Under aseptic technique the needle was inserted at a $45^{\circ}$ angle, caudal and slightly posteriorly and advanced until paresthesia was elicited to perform ISB. To perform ISB + SCPB, ISB was done first and then the same needle was withdrawn up, to the subcutaneous plane and field block was given. The block was performed by the same anesthesiologist to all the patients.

Conversion to general anesthesia (GA), requirement of supplemental analgesia and patient satisfaction were chosen as primary outcomes. The onset of sensory blockade, motor blockade and duration of analgesia were considered as secondary outcomes. Local and hemodynamic complications if any were noted and compared.

After 5 minutes (min) of block given, sensory and motor functions were assessed. Thereafter, they were assessed every $1 \mathrm{~min}$ till the sensory and motor blockade occurred or for the next 10 mins. Sensory function was assessed by exerting deep pressure on the fractured part and the motor function by asking the patient to lift the shoulder and flex the arm and tallying it with Medical Research Council Muscle Testing scale. Point of no pain and muscle testing scale $<2 / 5$ were considered onset of sensory and motor blockade respectively ${ }^{9}$.

Sensory block was considered inadequate if the patient complained of pain during the surgery. Either local infiltration of LA (3-5 ml Lignocaine with Adrenaline) or IV Fentanyl $80 \mathrm{mcg}$ were given as rescue analgesia. After completion of surgery, patients were asked to grade their level of satisfaction from 1 to 5 in regard to the regional anesthesia.

\begin{tabular}{|c|c|c|c|}
\hline 1 & Extremely Not Satisfied & 4 & Very Satisfied \\
\hline 2 & Not Satisfied & 5 & Extremely satisfied \\
\hline 3 & Moderately Satisfied & & \\
\hline
\end{tabular}

Table I: Five point Likert Scale for Satisfaction

\section{Statistical Analysis:}

Data was analyzed using SPSS 20. Independent T test, chi square test and Fishers exact test were used.

\section{RESULTS}

The mean age in Group I was $34 \pm 10.722$ and Group II was $28.93+9.534$ years. Although the gender distribution and right side clavicle fracture vs. left side clavicle fracture were statistically insignificant between the groups (Fig 1\&2), male gender and right side fracture were greater in both groups.
Exact Sig. $(2$ sided $)=1.000$

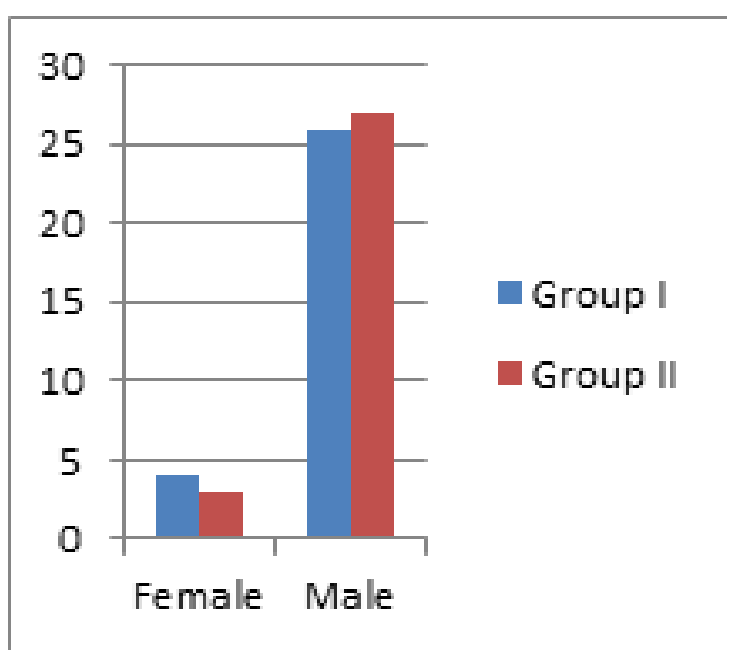

Fig 1: Comparison of female vs. male

Pearson $\mathrm{X}^{2}$ Asymp. Sig. $=0.781$

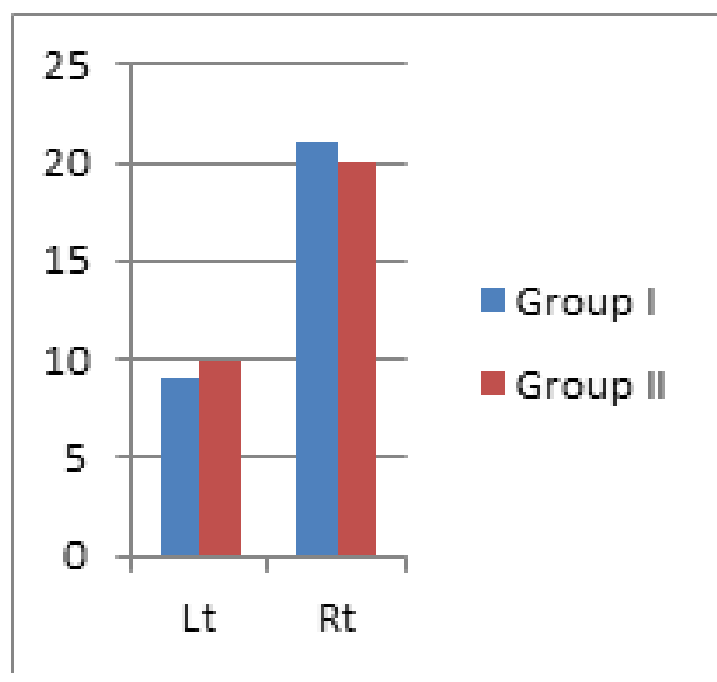

Fig 2: Comparison of Right vs. Left fractures

\begin{tabular}{|c|c|c|c|c|c|}
\hline & & \multicolumn{2}{|c|}{ Groups } & \multirow[b]{2}{*}{ Total } & \multirow{2}{*}{$\begin{array}{c}\text { Pearson X } \\
\text { Asymp. Sig. } \\
\text { (2-sided) }\end{array}$} \\
\hline & & $\underset{\text { I }}{\text { Group }}$ & Group & & \\
\hline \multirow{2}{*}{$\begin{array}{c}\text { Patient } \\
\text { satisfaction }\end{array}$} & Level 4 & 9 & 4 & 13 & \multirow{2}{*}{0.117} \\
\hline & Level 5 & 21 & 26 & 47 & \\
\hline \multirow{2}{*}{$\begin{array}{c}\text { Local } \\
\text { Anesthesia } \\
\text { top up/IV } \\
\text { Fentanyl }\end{array}$} & No & 22 & 28 & 50 & \multirow{3}{*}{0.038} \\
\hline & Yes & 8 & 2 & 10 & \\
\hline \multicolumn{2}{|c|}{ Total } & 30 & 30 & 60 & \\
\hline
\end{tabular}

Table II: Primary Outcomes of Anesthesia

The proportion of patient receiving the top up local analgesia or IV fentanyl was significantly greater in ISB only group. Still none of the patient in both the groups had satisfaction level less than 4 . Satisfaction level difference was statistically insignificant. There was no conversion to GA in both groups. 


\begin{tabular}{|c|c|c|c|c|c|}
\hline & Groups & $\mathbf{N}$ & Mean & $\begin{array}{c}\text { Std. } \\
\text { Deviation }\end{array}$ & $\begin{array}{c}\text { P } \\
\text { Value }\end{array}$ \\
\hline $\begin{array}{c}\text { Onset of } \\
\text { Sensory } \\
\text { Block (Min) }\end{array}$ & Group I & 30 & 7.8667 & 1.33218 & .539 \\
\cline { 2 - 6 } & Group II & 30 & 8.0667 & 1.17248 & \\
\hline $\begin{array}{c}\text { Onset of } \\
\text { Motor Block } \\
\text { (Min) }\end{array}$ & Group I & 30 & 8.7333 & 1.52978 & .651 \\
\cline { 2 - 6 } & Group II & 30 & 8.9000 & 1.29588 & \\
\hline $\begin{array}{c}\text { Duration of } \\
\text { Analgesia } \\
\text { (Hr) }\end{array}$ & Group I & 30 & 8.8667 & .73030 & .377 \\
\cline { 2 - 6 } & Group II & 30 & 9.0333 & .71840 & \\
\hline
\end{tabular}

Table III: Secondary Outcomes of Anesthesia

The differences of onset of sensory block, onset of motor block and duration of analgesia between the groups were significantly insignificant.

There was no significant difference in the occurrence of horner's syndrome and hoarseness of voice between the groups. Respiratory difficulty, hypertension, hypotension, tachycardia and bradycardia were present in none of the patients of both groups.

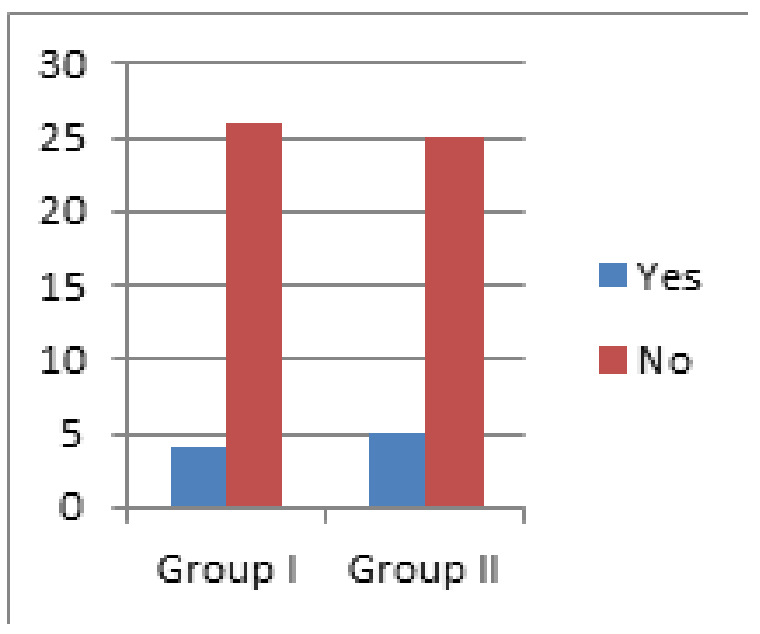

Fig 3: Horner's Syndrome

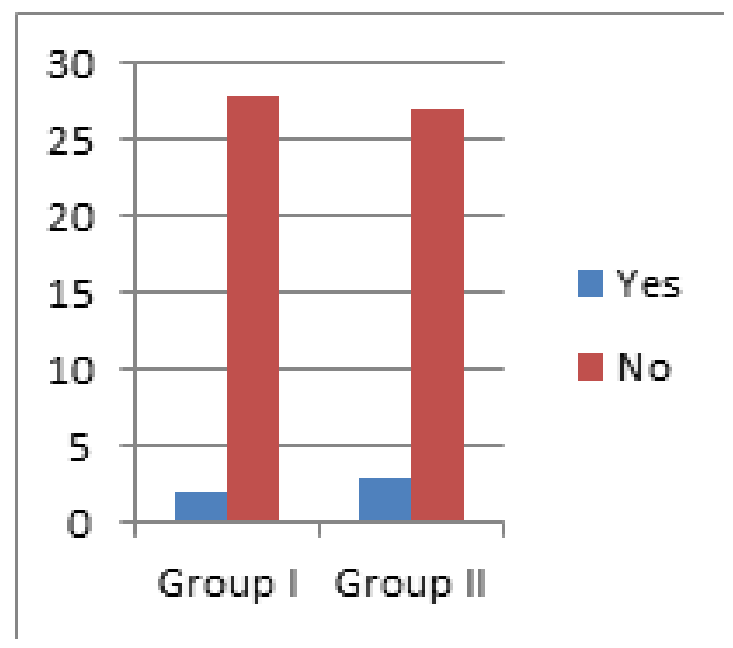

Fig 4: Hoarseness of Voice

\section{DISCUSSION}

Due to complex and varied innervations of clavicle, its surgeries are mostly performed under general anesthesia $(G A)^{10,11}$. Till now very few studies regarding regional anesthesia in clavicle surgeries are done. Most of those studies show that regional anesthesia techniques are effective ${ }^{2,5,12}$. Fear of block failure has been overcome with regular use of regional anesthesia. Anesthesiologists now are trying to find out the optimal and safe method of regional anesthesia for clavicle surgeries.

In our study we compared efficacy of ISB alone with ISB + SCBP. The study showed that the need of supplemental analgesia in form of either LA top up or IV fentanyl was significantly greater in ISB only group. This result is similar to the study conducted by Gupta N. But in contrast to their study where GA was required in both the groups, none of the patients in our study required $\mathrm{GA}^{8}$. This might be because, in our study, all patients in both groups perceived paresthesia during ISB, even without the use of nerve stimulator, which indicates direct contact of the needle with the nerve in the plexus.

Although the use of supplemental analgesia was significantly greater in ISB group, the patient satisfaction level in both groups was high and almost equal. This might be because all patients were preoperatively counseled and assured that pain if present during the surgery will be immediately treated. Similarly, in the intraoperative period, reassurance was done and supplemental analgesia was given immediately to the one who perceived pain due to partial block. No conversion to GA might have also increased their satisfaction level.

Ultrasound-guided (USG) blocks are becoming popular day by day $^{13}$. The use of USG improves the onset and completeness of sensory and motor blocks ${ }^{14}$. In a randomized study, Kapr al et al showed that ultrasound guidance was $99 \%$ successful in achieving surgical anesthesia with ISB compared with $91 \%$ for landmark ${ }^{15}$. Still a large number of anaesthesiologists do not have access to USG ${ }^{13}$. This study clearly depicts that ISB or ISB + SCPB given blindly can be useful to avoid GA for clavicular plating in such setups.

\section{CONCLUSION}

Interscalene block combined with Superficial Cervical Plexus Block (ISB + SCPB) has better efficacy than Interscalene block (ISB) alone for clavicular plating. Nevertheless, both techniques avoid GA and provide excellent patient satisfaction level.

\section{REFRENCES}

1. Pecci M, Kreher JB. Clavicle fractures. Am Fam Physician. Jan 2008;77(1):65-70.

2. Potsangbam S, Kay JP. Efficacy of Combined Interscalene Block and Superficial Cervical Plexus Block for Surgeries of the Clavicle: A Prospective Observational Study. Journal of Clinical and Diagnostic Research. Feb 2019;13(2).

3. Shrestha BR, Sharma P. Regional Anaesthesia in Clavicle Surgery. J Nepal Med Assoc. 2017;56(206):265-67.

4. Tran DQ, Tiyaprasertkul W, González AP. Analgesia for clavicular fracture and surgery: a call for evidence. Reg Anesth Pain Med. Nov-Dec 2013;38(6):539-43. 
5. Rajbanshi LK, Arjyal B, Khanal K, Bajracharya A. Comparison of Ultrasound Guided Interscalene and Supraclavicular Brachial Plexus Block along with Superior Cervical Plexus Block for Clavicle Fracture Surgery. Journal of College of Medical Sciences. Oct-Dec 2018;14(4).

6. Gurumoorthi P, Mistry T, Sonawane KB, Balasubramanian S. Ultrasound guided selective upper trunk block for clavicle surgery. Saudi J Anaesth. 2019;13(4):394-5.

7. Singh SK. The Cervical Plexus: anatomy and ultrasound guided blocks. Anaesthesia, Pain and Intensive Care. Jul- Sep 2015;19(3):323-2.

8. Gupta N, Gupta V, Kumar G, Gupta DK. Comparative evaluation of efficacy of interscalene block vs. interscalene block and superficial cervical plexus block for fixation of clavicular fractures. International Journal of Contemporary Medical Research. March 2019;(3).

9. Sluga TP, Stieger MG, Posch M et al. Reliability and validity of thr medical research council (MRC) scale and a modified scale for testing muscle strength in patients with radial palsy. J Rehabil Med 2008; 40: 665-671.

10. Reverdy F. Combined interscalene-superficial cervical plexus block for clavicle surgery: an easy technique to avoid general anesthesia.BJA. Oct 2015;115,suppl.

11. McHardy P. Interscalene vs. superficial cervical block vs. combination for analgesia after clavicle fracture. U.S. National library of medicine. Available from: https://clinicaltrials.gov/ ct2/show/NCT03094481.

12. Balaban O, D "ulgero ־glu TC, Aydin T. Ultrasound-Guided Combined interscalene-cervical plexus block for surgical anesthesia in clavicular fractures: A retrospective observational study. Anesthesiology research and practice. Jun2018. Available from:https://doi.org/10.1155/2018/7842128

13. Vaid V.N, Shukla A. Interscalene block: revisiting old technique. Anesthesia, essays and researches. 2018; 12(2): 344-48.

14. Ahuja K, Dureja J, Chaudhary G, Middha S. A Comparative Evaluation of Techniques in Interscalene Brachial Plexus Block: Conventional blind, Nerve Stimulator Guided and Ultrasound Guided. Ann.Int.Med.Den.Res. 2016;2(3):61.

15. Kapral S, Greher M, Huber G, et al. Ultrasonographic guidance improves the success rate of interscalene brachial plexus blockade. Reg Anesth Pain Med 2008; 33:253-258. 